\title{
Risk assessment in patients with gastrointestinal bleeding
}

\author{
Charoen Mankongpaisarnrung MD, Kunut Kijsirichareanchai MD, Matthew Soape MD, Ariwan Rakvit MD
}

CASE

A 59-year-old woman presents to the emergency room with 2-3 weeks of increasing weakness. She has also noted an occasional melenic stool. Her past history is unremarkable. Her vital signs include a pulse rate of $102 \mathrm{bpm}$ and a systolic blood pressure of $96 \mathrm{mmHg}$. Her significant labs were: hemoglobin $10 \mathrm{gm} / \mathrm{dl}$, BUN $28 \mathrm{mg} / \mathrm{dl}$, and INR 1.4. How can we assess this patient?

\section{Discussion}

Upper gastrointestinal (GI) bleeding is one of the most common medical problems needing hospital admission. To provide adequate medical care and appropriate medical resource utilization, several clinical and endoscopic scoring systems have been developed, implemented, and internally and externally validated. The initial evidence suggests that these scoring systems can improve clinical decision-making.

GI bleeding can be classified into two groups based on the anatomical location of bleeding - upper $\mathrm{GI}$ bleeding and lower $\mathrm{GI}$ bleeding. This classification uses the ligament of Treitz, located between the $4^{\text {th }}$ part of the duodenum and jejunum. Based on endoscopic finding, upper Gl bleeding can be further categorized into variceal bleeding or non-variceal bleeding. This approach can guide physicians to what treatment is needed for individual patients. Patients with $\mathrm{Gl}$ bleeding can present with vague or non-specific symptoms until overt and massive bleeding, such as hematemesis, melena, or hematochezia, occurs.

Corresponding author: $C$ Mankongpaisarnrung, $M D$ Contact Information: Charoen.mankongpaisarnrung@ ttuhsc.edu

DOI: 10.12746/swrccc2013.0104.039
Hospital admissions for $\mathrm{Gl}$ bleeding in the United States account for up to $10 \%$ of all hospitalizations and cost 3,180-8,990 US dollars per admission. ${ }^{1,2}$ The severity of Gl bleeding affects mortality and hospital cost. ${ }^{3}$ Furthermore, elderly patients will have worse outcomes and higher mortality rates since they often have multiple comorbidities. ${ }^{4}$ To provide the best medical care and to use resources optimally in some hospital settings, several researchers developed tools for risk stratification by identifying and distinguishing between high-risk patients and low risk patients. The goal is to anticipate the risk of rebleeding within 30 days, hospital mortality, urgent endoscopic treatment, and the need for ICU admission. Also, these tools could provide prognostic information regarding the length of hospital stay. ${ }^{5}$ The literature suggests that the mortality of patients with non-variceal GI bleeding admitted to a GI service is lower than those admitted to an internal medicine service. ${ }^{6}$ Therefore, the evaluation of severity of Gl bleeding is important to identify who will receive the most benefit from hospitalization for close monitoring and aggressive resuscitation.

\section{GI BLEEDING RISK ASSESSMENT TOOLS}

Clinical evaluation, including the presence or absence of postural symptoms and the assessment of hemodynamic status by monitoring vital signs, urine output, level of consciousness, and estimated blood loss, is very important when managing patients with upper $\mathrm{Gl}$ bleeding. In addition, clinical presentation, age, and comorbidities are important factors. As a standard of care for the treatment of Gl bleeding, patients with hemodynamic compromise need immediate resuscitation and endoscopy within 24 hours after admission. ${ }^{1}$

The best-established GI bleeding scoring sys- 
tems include the Rockall score $^{7}$ and the GlasgowBlatchford score (GBS). ${ }^{8}$ Recently, the AIM65 was also found to be useful. ${ }^{9}$

Some studies have demonstrated that clinical decisions made by certified emergency physicians are also important and perhaps more useful than using a Gl bleeding score tool in triage decisions either to admit the patient or to discharge the patient to outpatient evaluation. ${ }^{10,11}$ However, there has only been one clinical study in the US regarding the use of a GI bleeding scoring system to triage into an ICU or nonICU bed. ${ }^{12}$

\section{UPPER GI BLEEDING SCORING SYSTEMS}

1. Pre-endoscopic Rockall score and complete Rockall score

2. Glasgow-Blatchford score (GBS)

\section{Pre-endoscopic Rockall score and com- PLETE ROCKALL SCORE ${ }^{5}$}

This scoring tool may help predict the risk on in-hospital bleeding and/or mortality. At the initial evaluation before endoscopy, patients can be evaluated using the pre-endoscopic Rockall score. Patients are assigned point values for each of the clinical variables (age, shock, and comorbidity) and endoscopic variables (diagnosis and stigmata of recent hemorrhage). The Rockall score is equal to the sum of the points assigned. Scores can range from 0-7 for the preendoscopic score and 0-11 points for the complete score. Patients with complete Rockall scores of 2 or less are considered low risk for developing adverse outcomes (rebleeding $4 \%$, mortality $<0.1 \%$ ). Patients with a pre-endoscopic Rockall score of 0 are considered low risk. This scoring system may help anticipate the risk of in-hospital bleeding and mortality.

\begin{tabular}{|c|c|c|c|c|}
\hline \multicolumn{5}{|c|}{ Rockall Scoring System } \\
\hline Variable & Score $=0$ & Score $=1$ & Score $=2$ & Score $=3$ \\
\hline Age (years) & $<60$ & $60-79$ & $>80$ & \\
\hline Comorbidity & & & $\begin{array}{c}\text { Congestive heart } \\
\text { failure, ischemic } \\
\text { heart disease }\end{array}$ & $\begin{array}{l}\text { Renal failure, liver } \\
\text { disease, metastatic } \\
\text { disease }\end{array}$ \\
\hline Shock & No shock & Pulse $>100 \mathrm{bpm}$ & $\begin{array}{c}\text { Systolic BP }<100 \\
\mathrm{mmHg}\end{array}$ & \\
\hline Source of bleeding & $\begin{array}{c}\text { Mallory-Weiss } \\
\text { Tear }\end{array}$ & $\begin{array}{l}\text { All other diagno- } \\
\text { ses: e.g., esophagi- } \\
\text { tis, gastritis, peptic } \\
\text { ulcer disease, } \\
\text { varices }\end{array}$ & Malignancy & \\
\hline $\begin{array}{c}\text { Stigmata of recent } \\
\text { bleeding }\end{array}$ & None & & $\begin{array}{l}\text { Adherent clot or } \\
\text { spurting vessel }\end{array}$ & \\
\hline
\end{tabular}

\section{GLASGOW-BLATCHFORD SCORE ${ }^{10}$}

Patients with upper $\mathrm{Gl}$ bleeding who have a total GBS of $\mathbf{0}$ are considered low risk. These patients can be discharged from the emergency room without admission and/or in-hospital intervention. Instead, early out-patient endoscopy would be a more effective option. This scoring system has also been shown to anticipate the risk of intervention (blood transfusion, endoscopic or surgical therapy) and death. Many studies have found it to be a simple and useful scoring system when applied to triage patients in emergency rooms awaiting endoscopic results. ${ }^{13}$ 


\begin{tabular}{|c|c|c|c|}
\hline \multicolumn{3}{|c|}{ Glasgow-Blatchford Scoring System } & \multirow[b]{2}{*}{ BUN (mmol/L) } \\
\hline BUN (mg/dL) & $<18$ & 0 & \\
\hline & $18-22$ & 2 & $6.5-<8$ \\
\hline & $23-27$ & 3 & $8-<10$ \\
\hline & $28-70$ & 4 & $10-<25$ \\
\hline & $>70$ & 6 & $>25$ \\
\hline \multirow[t]{4}{*}{$\begin{array}{l}\text { Hemoglobin } \\
(\mathrm{men}, \mathrm{g} / \mathrm{dL}) \\
\end{array}$} & $>13$ & 0 & \\
\hline & $12-12.9$ & 1 & \\
\hline & $10-11.9$ & 3 & \\
\hline & $<10$ & 6 & \\
\hline \multirow[t]{3}{*}{$\begin{array}{c}\begin{array}{c}\text { Hemoglobin (wom- } \\
\text { en, g/dL) }\end{array} \\
\end{array}$} & $>12$ & 0 & \\
\hline & $10-11.9$ & 1 & \\
\hline & $<10$ & 6 & \\
\hline \multirow[t]{4}{*}{$\begin{array}{l}\text { Systolic blood pres- } \\
\text { sure (mmHg) } \\
\end{array}$} & $>110$ & 0 & \\
\hline & $100-110$ & 1 & \\
\hline & $90-99$ & 2 & \\
\hline & $<90$ & 3 & \\
\hline \multirow[t]{5}{*}{ Other markers } & Pulse $>100$ bpm & 1 & \\
\hline & $\begin{array}{c}\text { Presentation of } \\
\text { melena }\end{array}$ & 1 & \\
\hline & $\begin{array}{c}\text { Presentation of } \\
\text { syncope }\end{array}$ & 2 & \\
\hline & Hepatic disease & 2 & \\
\hline & Cardiac failure & 2 & \\
\hline
\end{tabular}

\section{REMARK:}

${ }^{* *}$ Hepatic disease $=$ known history or clinical/laboratory evidence of chronic or acute liver disease

** Cardiac failure $=$ known history of clinical/echocardiographic evidence of cardiac failure

\section{AIMS65 SCORE}

Patients with upper $\mathrm{GI}$ bleeding who have the total AIMS65 of 1 or less are considered at low risk.

\begin{tabular}{|c|c|}
\hline Clinical parameters & Score value \\
\hline Albumin level $<3.0 \mathrm{~g} / \mathrm{dL}$ & 1 \\
\hline INR level $>1.5$ & 1 \\
\hline Altered mental status & 1 \\
\hline $\mathrm{SBP} \leq 90 \mathrm{mmHg}$ & 1 \\
\hline Age $>65$ & 1 \\
\hline
\end{tabular}




\section{COMPARISON OF GI BLEEDING SCORING TOOLS}

Gralnek, et al. concluded that the complete Rockall score helps identify more low risk patients (complete Rockall score less than 2) than the pre-endoscopic Rockall score or GBS. ${ }^{14}$ However, another study demonstrated that the GBS is more effective than the pre-endoscopic Rockall score. ${ }^{11}$ Since the complete Rockall score requires endoscopy results for its scoring, it cannot be utilized in the clinical settings where endoscopy cannot be performed soon after evaluation in the emergency room. Clinical evaluation and the use of a clinical scoring system such as the pre-endoscopic Rockall score would help triage this group of patients. ${ }^{5}$ The GBS can better predict clinical outcomes of death, the need for blood transfusion, endoscopic therapy, or surgery than the complete Rockall score. ${ }^{15,16}$ Another study reported that the GBS identified high risk patients with variceal hemorrhage needing intervention; however, it was not useful in predicting mortality. ${ }^{17}$

\section{CASE REVIEW using SCORING tOOLS}

Our patient presents with symptomatic anemia, most likely from $\mathrm{Gl}$ bleeding given the melenic stools. She has a low BP and tachycardia likely secondary to blood loss. Her estimated blood loss would be $15-30 \%$ since she is tachycardic but there is no other information regarding orthostasis. She needs immediate fluid resuscitation and hospitalization for evaluation.

Using the upper $\mathrm{Gl}$ bleeding scoring systems discussed, her calculated pre-endoscopic Rockall score would be 3 from tachycardia (pulse > $100 \mathrm{bpm}$ ) and low blood pressure $(<100 \mathrm{mmHg}$ ). Her GBS would be 9 from her BUN level, hemoglobin level, heart rate, systolic blood pressure, and presentation of melena. Therefore, this patient would be stratified as high risk by both scoring systems, requiring immediate resuscitation and urgent endoscopic evaluation.

\begin{tabular}{|c|c|c|}
\hline $\begin{array}{l}\text { Scoring } \\
\text { system }\end{array}$ & Clinical Rockall score & Glasgow- Blatchford score \\
\hline & Age of $59(<60)=0$ & BUN $28(28-70)=4$ \\
\hline & No underlying comorbidities $=0$ & $\begin{array}{c}\text { Hemoglobin } 10 \\
(\text { female } 10-11.9)=1\end{array}$ \\
\hline & $\begin{array}{c}\text { Pulse }>100 \text { bpm }=1 \\
\text { Systolic BP } 96 \\
\operatorname{mmHg}(<100) \quad=2\end{array}$ & Systolic BP 96 mmHg =2 \\
\hline & $\begin{array}{l}\text { No information about source of } \\
\text { bleeding = NA }\end{array}$ & Pulse $>102$ bpm $=1$ \\
\hline & $\begin{array}{l}\text { No information about stigmata of } \\
\text { recent bleeding = NA }\end{array}$ & Melena $=1$ \\
\hline & & $\begin{array}{l}\text { No known cardiac/hepatic dis- } \\
\text { ease }=0\end{array}$ \\
\hline Total score & 3 & 9 \\
\hline
\end{tabular}




\section{RECOMMENDATIONS}

Upper $\mathrm{Gl}$ bleeding scoring systems are useful instruments to help evaluate patients with upper GI bleeding. However, clinical acumen is also important and necessary to provide the best level of medical care to patients with upper GI bleeding. With the use of a scoring system, low risk patients can be identified more effectively and triaged to less costly care.

\section{KEY POINTS}

1. Detailed clinical evaluation and hemodynamic assessment can risk stratify patients with upper $\mathrm{Gl}$ bleeding.

2. Upper $\mathrm{Gl}$ bleeding scoring tools can assist physicians in the triage of patients. However, the scoring system cannot substitute for clinical acumen. In order to provide the most appropriate level of medical care, incorporating an upper Gl bleeding scoring system into a clinical practice should allow internists to evaluate patients with $\mathrm{GI}$ bleeding requiring hospitalization more effectively.

3. Low risk criteria in the different upper GI bleeding scoring system are listed below.

- $\quad$ Pre-endoscopic Rockall score of 0 and complete Rockall score of 2 or less

- Predict the risk of further bleeding and death

- $\quad$ GBS of 0

- Predicts the risk of intervention and death

- AIMS65 of 1 or less

4. Patients with upper GI bleeding who have the total GBS of 0 are considered low risk, and they can be discharged from emergency department safely with $<1 \%$ chance of requiring an immediate intervention after discharge.

KEY WORDS- Upper gastrointestinal bleeding, upper GI bleeding scoring system Rockall score, Glasgow Blatchford score
Author Affiliation: Charoen Mankongpaisarnrung, Kunut Kijsirichareanchai, and Matthew Soape are residents in Internal Medicine at TTUHSC. Ariwan Rakvit is a gastroenterologist in the Department of Internal Medicine at TTHUSC.

Received: 4/2/2013

Accepted: 9/6/2013

Reviewers: Sreeram Parupudi MD, Isham Huizar MD

Published electronically: 10/15/2013

Conflict of Interest Disclosures: None

\section{REFERENCES}

1. Laine L, Jensen DM. Management of patients with ulcer bleeding. Am J Gastroenterol 2012;107:345-60; quiz 61.

2. Parker DR, Luo X, Jalbert JJ, Assaf AR. Impact of upper and lower gastrointestinal blood loss on healthcare utilization and costs: a systematic review. J Med Econ 2011;14:279-87. 3. Pardo A, Durandez R, Hernandez M, et al. Impact of physician specialty on the cost of nonvariceal upper GI bleeding care. Am J Gastroenterol 2002;97:1535-42.

4. Theocharis GJ, Arvaniti V, Assimakopoulos SF, et al. Acute upper gastrointestinal bleeding in octogenarians: clinical outcome and factors related to mortality. World J Gastroenterol 2008; 14:4047-53.

5. Tham TC, James C, Kelly M. Predicting outcome of acute non-variceal upper gastrointestinal haemorrhage without endoscopy using the clinical Rockall score. Postgrad Med J 2006;82:757-9.

6. Sandel MH, Kolkman JJ, Kuipers EJ, Cuesta MA, Meuwissen SG. Nonvariceal upper gastrointestinal bleeding: differences in outcome for patients admitted to internal medicine and gastroenterological services. Am J Gastroenterol 2000;95:2357-62.

7. Bessa X, O'Callaghan E, Balleste B, et al. Applicability of the Rockall score in patients undergoing endoscopic therapy for upper gastrointestinal bleeding. Dig Liver Dis 2006;38:12-7.

8. Blatchford O, Murray WR, Blatchford M. A risk score to predict need for treatment for upper-gastrointestinal haemorrhage. Lancet 2000;356:1318-21.

9. Saltzman JR, Tabak YP, Hyett BH, Sun X, Travis AC, Johannes RS. A simple risk score accurately predicts in-hospital mortality, length of stay, and cost in acute upper GI bleeding. Gastrointest Endosc 2011;74:1215-24.

10. Chandra S, Hess EP, Agarwal D, et al. External validation 
of the Glasgow-Blatchford Bleeding Score and the Rockall Score in the US setting. Am J Emerg Med 2012;30:673-9. 11. Pang SH, Ching JY, Lau JY, Sung JJ, Graham DY, Chan FK. Comparing the Blatchford and pre-endoscopic Rockall score in predicting the need for endoscopic therapy in patients with upper GI hemorrhage. Gastrointest Endosc 2010;71:1134-40.

12. Farooq FT, Lee MH, Das A, Dixit R, Wong RC. Clinical triage decision vs risk scores in predicting the need for endotherapy in upper gastrointestinal bleeding. Am J Emerg Med 2012;30:129-34.

13. Koksal O, Ozeren G, Ozdemir F, Armagan E, Aydin S, Ayyildiz T. Prospective validation of the Glasgow Blatchford scoring system in patients with upper gastrointestinal bleeding in the emergency department. Turk J Gastroenterol 2012;23:448-55.

14. Gralnek IM, Dulai GS. Incremental value of upper endoscopy for triage of patients with acute non-variceal upper-GI hemorrhage. Gastrointest Endosc 2004;60:9-14.

15. Stanley AJ, Dalton HR, Blatchford O, et al. Multicentre comparison of the Glasgow Blatchford and Rockall Scores in the prediction of clinical end-points after upper gastrointestinal haemorrhage. Aliment Pharmacol Ther 2011;34:470-5.

16. Stanley AJ. Update on risk scoring systems for patients with upper gastrointestinal haemorrhage. World J Gastroenterol 2012;18:2739-44.

17. B Reed, H R Dalton, O Blatchford, D Ashley, et al. Is the Glasgow Blatchford Score useful in the risk assessment of patients presenting with variceal haemorrhage? Gut 2011;60:A45. 